CuO 武佯中的卤素时, 对这两元素所达到的灵解度 是 $0.15 \%$ 。他每次曝光所用的試样量約为 0.5 克。而 在我們的实驗中只用 0.3 克。可以預料, 在实驗中如 能像 Левинтов 一样使用光圈和色散率都此較大的 三个俊鏡的摄譜仪，增大試样用量，扞选用更佳的激 唚及蒸条件, 則灵敏度当可更提高。

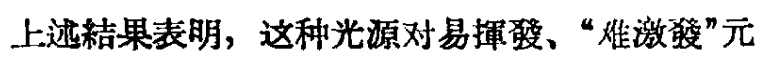
素的光譜分析是有一定的优点的。由于它能把試样的 蒸没激过程完全分开，所以还可以利用它来研究 一下到底是大电容还是小电容的低压电花对“难激墢” 元素的激郋更有利 (Pfeilsticker [4] 用几百 $\mu$ F 以上 菂电容在低气压下来激骠这类元素的光譜)。我們正 在准备对它作进一步的研究, 讲准备用它来作 $\mathrm{Cl}$ 、 $\mathrm{Br} 、 \mathrm{Se}$ 等元素的測定。

\section{黄本立田笠 楖}

(中国科学院应用化学研究所) (南京大学化学采)

\section{7 年 11 月 15 日}

[1 1] 黄本立, 科学通报, 1957 年第 10 期, 第298頁。

[2 2$]$ Bardócz, Á., Acta Physica Acad. Sci. Hungaricaen 1(3), 247(1952).

[2] Лөвинтов, И. И, Журн. тех. физ., 17 (7), 795 (1947).

[5] Pieilsticker, K., (a) Spectrochim. Acta, 1, 424 (1940), (b) Mikrochim. Acta, 1955, Heft 2-3, 358.

\section{乙酸乙酯对硝酸鈰 $(\mathbf{I V})$ 的溶剂萃取}

早在 1927 年, Imre [1]已报导了利用乙醚在硝酸 溶液中萃取銅 (IV) 的試驗, 得到了良好䊅果。此后 又有許多学者如 Bock [2]、Gryder [3]、Wylie ${ }^{[4]}$ 及

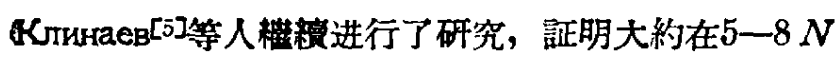

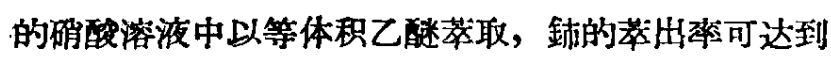
90-95\%左右。此外, Warf[6] 采用磷酸三丁酯萃取 硝酸鈰鈘，也有利用硝基里烷 ${ }^{[7]}$ 及各种醇类作錰的萃 取者，这些方法各有其优触点。

作者进行了醚、酷、䣱、醇等十余种有机溶剂对 硝酸鈰敛的萃取, 除驗証了 Imre 的結果外, 愣了 乙酸乙酯在硝酸介質中对鋪等体积单次萃出率能高达 $90 \%$ 以上，在有机相比水相体积为 50 毫仆比 25 毫升 时萃出为为 $93.89 \%$ 。因而进一步进行了乙酸乙酷萃

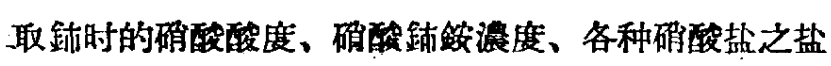
析效应对分配影响的研究。最后还进行了巨經光䜊全 定量的希土混合物中鈰的萃取，菻出本为 $92.21 \%$, 以 50 毫升溶剂比 25 毫升試料体积莁取时萃出本可
达 $94.86 \%$ ，两者純度皆为 $96 \%$ 左右，經光譛定性磷 定其他希土杂質为 La 及 $\mathrm{Y}$ 元来。实驗中还测走了各

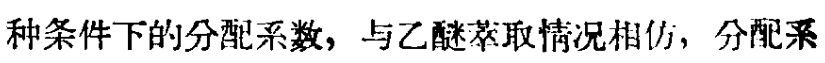
数扭不是一常数值。現将主要谈驗絬果列于下表。

表 1 酸度对鋪猝取之影响

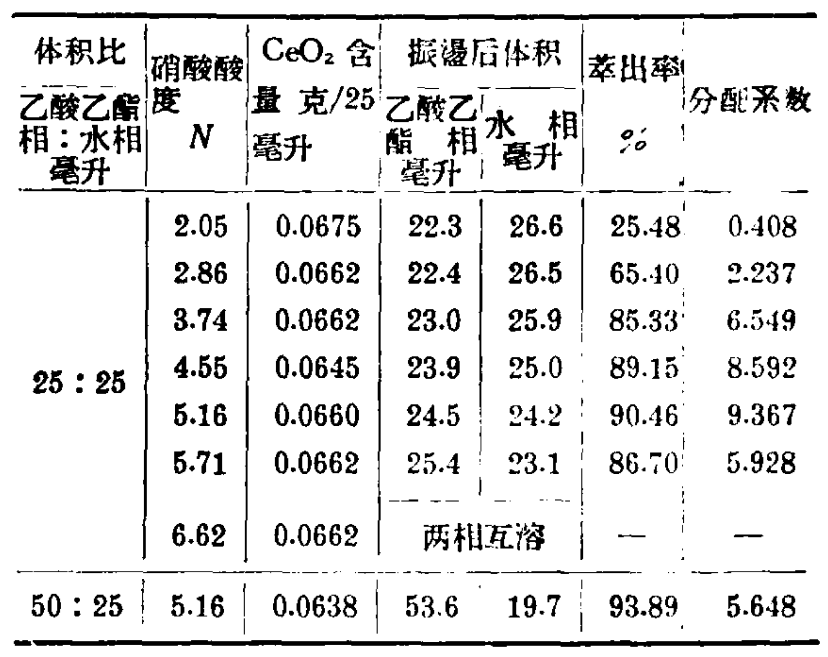

表 2 碓酸触銨農度对葆取之影响

\begin{tabular}{|c|c|c|c|c|c|}
\hline \multirow{2}{*}{$\begin{array}{l}\mathrm{CeO}_{2} \text { 含 } \\
\text { 貫克/25 } \\
\text { 严 }\end{array}$} & \multirow{2}{*}{\begin{tabular}{|c|} 
䂤酸酸度 \\
$N$ \\
\end{tabular}} & \multicolumn{2}{|c|}{ 层鼠后体积 } & \multirow{2}{*}{ 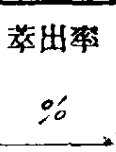 } & \multirow{2}{*}{ 分配柔数 } \\
\hline & & 乙酸乙醋 & 水 相 & & \\
\hline 0.0320 & 5.11 & 25.2 & 23.9 & 76.26 & 3.047 \\
\hline 0.0660 & 5.16 & 24.5 & 24.2 & 90.46 & 9.367 \\
\hline 0.1380 & 5.10 & 24.6 & 24.0 & 89.91 & 8.698 \\
\hline 0.3375 & 5.21 & 25.3 & 23.3 & 90.33 & 8.604 \\
\hline 0.6459 & 5.38 & 27.0 & 21.4 & 89.32 & 6.628 \\
\hline
\end{tabular}

表 3 盐析效照

\begin{tabular}{|c|c|c|c|}
\hline 盐析 剂 & 菻出车只。 & 盐利剂 & 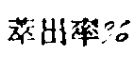 \\
\hline - & 25.48 & $\mathrm{Ca}\left(\mathrm{NO}_{3}\right)_{2}$ & 92.39 \\
\hline $\mathrm{NH}_{4} \mathrm{NO}_{3}$ & 67.10 & $\mathrm{Mg}\left(\mathrm{NO}_{3}\right)_{2}$ & 92.53 \\
\hline $\mathrm{LiNO}_{3}$ & 84.16 & $\mathrm{Zn}\left(\mathrm{NO}_{3}\right)_{2}$ & 80.54 \\
\hline $\mathrm{NaNO}_{s}$ & 90.20 & $\mathrm{Al}\left(\mathrm{NO}_{3}\right)_{3}$ & 84.20 \\
\hline
\end{tabular}

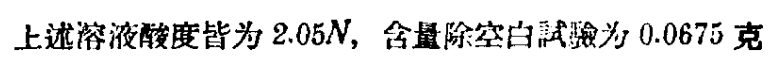
$\mathrm{CeO}_{2}$ 外, 其余皆为 0.0684 克 $\mathrm{CeO}_{2}$ 。姿碓酸酸度为 $5.16 \mathrm{~N}$

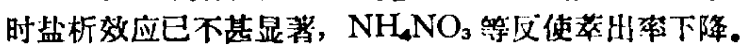

表 4 希土混合物之菻取

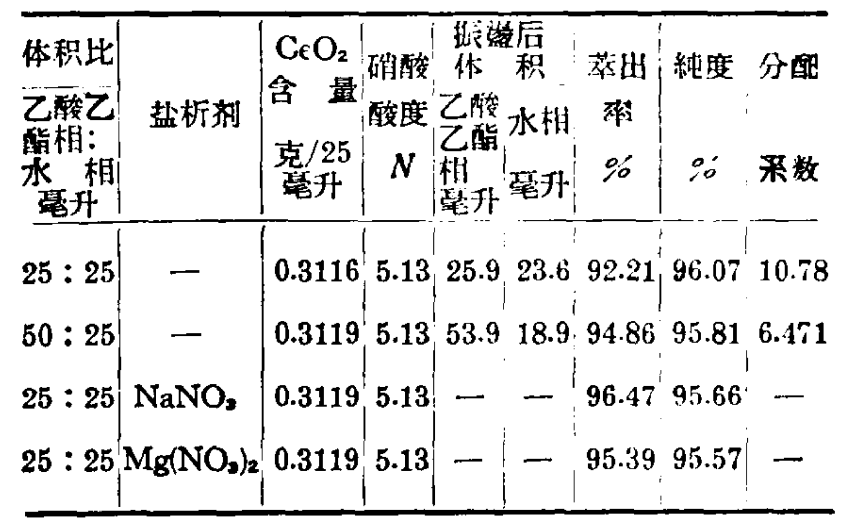

上述試料中 $\mathrm{CeO}_{2}$ : 其他常土約为 $1: 1$ 左右。 
实驗結果說明，乙酸乙酯对硝酸鈰敍或希土混合 物溶液中鈰的萃取能得到相当高的萃出本。

姥克敏 减弡石 鍾煥邦

(中田科学院应用化学研究所, 复且大学)

1957 年 11 月 12 日

[1] L. Imre, Z. anorg. Chem., 164, 214(1927).

[2] R. Bock und E. Bock, Naturwissenschatten, 36, 344 (1949); Z. anorg. allgem. Chem., 263, 146 (1950).

[3] J. W. Gryder and R.W. Dodson, J. Am. Chem. Soc., 71, 1894(1949).

[4] A. W. Wylie, J. Chem. Soc., 1474(1951).

[5] В.М. Клинаев и М. М. Сөнявин, "Примөнение Моченых Атомов в Аналитической Химии",118(1955).

[6] J. C. Warf, J. Am. Chem. Soc., 71, 3257(1949).

[ 7] U.S. 2,523, 892, Sept. 26(1950).

\section{青木香酸的結构}

青木香酸(I) 是我們在土青木香Aristolochia dobilis, S. et Z.) 中分得的一种新的化合物 [1]，它的分 子式是 $\mathrm{C}_{18} \mathrm{H}_{13} \mathrm{O}_{7} \mathrm{~N}$, 熔点 $>300^{\circ}$ (分解), $R_{A}^{*}=0.87$, 甲酯 (II) $\mathrm{C}_{19} \mathrm{H}_{15} \mathrm{O}_{7} \mathrm{~N}$ ，熔点 $260^{\circ}$ ，与馬盶鈴酸甲酯 (IV) (熔点 $\left.265^{\circ}\right)$ 混熔点显著下降 $\left(235-240^{\circ}\right)$ 。<smiles>COc1cccc2c1cc([N+](=O)[O-])c1c(CO)cc3c(c12)OCO3</smiles>

(I)

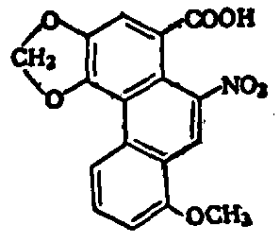

(III)
青木香酸跟与它共存的馬鬼鈴酸 (III) 性能極为 相似：遇湦硫酸变綠色，在歔性溶液中呈紅色，它的

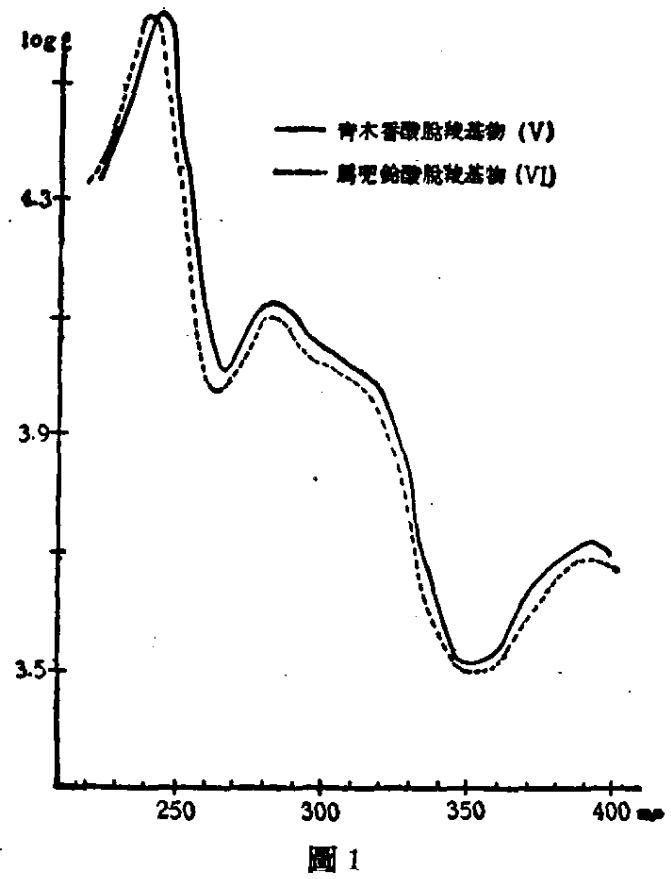

溶解度比 (III) 更小，几乎在所有的常用溶㭪中均很!

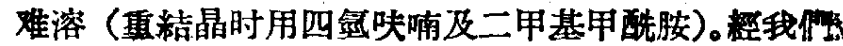
証明，(I) 同样也是一种天然含硝基的有机化合物。

为进一步研究青木香酸的結构，(I) 桱脫羭基反: 应后，得到黄色炣状結晶 (V)，分子式 $\mathrm{C}_{16} \mathrm{H}_{\Perp} \mathrm{O}_{5} \mathrm{~N}$, 塎点 $206^{\circ}$ ，与馬笔鈴酸的脫羭基物 (VI) 混熔点不下 降。(V)、(VI) 的紫外光譜也完抙一致 (圖 1)，因此証明 (I) 具有 (VI) 的部分結构, 井可把 (I) 的部分 䊅构式写为:

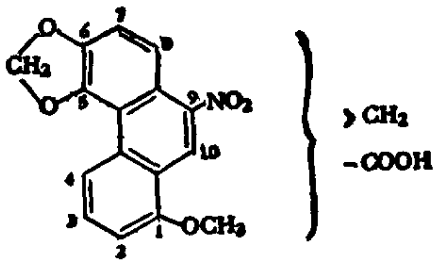

( $\left.\mathrm{I}_{\mathrm{A}}\right)$

（V） 又櫂 Karrer 改良的 Kohn-Roth 微量氧化法証明井無 $\mathrm{C}-\mathrm{CH}_{3}$ 基，因此上述 $\left(\mathrm{I}_{A}\right)$ 式中的 $>\mathrm{CH}_{2}$ : 排列显然不可能是作为甲基直接接在核上, 所以耕下 唯一的可能就是以一 $\mathrm{CH}_{2} \mathrm{COOH}$ 形式存在（但这样: 对于脫羧基反应的解粰份須深入研究）。<smiles>COc1cccc2c1cc([N+](=O)[O-])c1ccc3c(c12)OCO3</smiles>

$(\mathrm{V})=(\mathrm{VI})$<smiles>COc1cccc2c1cc1c3c(cc4c(c32)OCO4)OCO1</smiles>

(VIII)
从韭屬衍生物的吸收曲地较, 各种不同結构在 光輩中的差开主要表現在 $\lambda_{2}$ 与 $\lambda_{3}$ 二个波区。从表 (1) 可見，(I) 在 $\lambda_{2}$ 的 $\varepsilon$ 值比諸 (III) 再低得多; 按苯乙酸比諸莱甲酸，其 $N \rightarrow V_{1}$ 的吸收峰（在 270 。 $\mathrm{m} \mu$ 的B-band）也大为低落[2]，因之，(I）的跲基她。 有坬立（isolated）的可能（圖 2)。

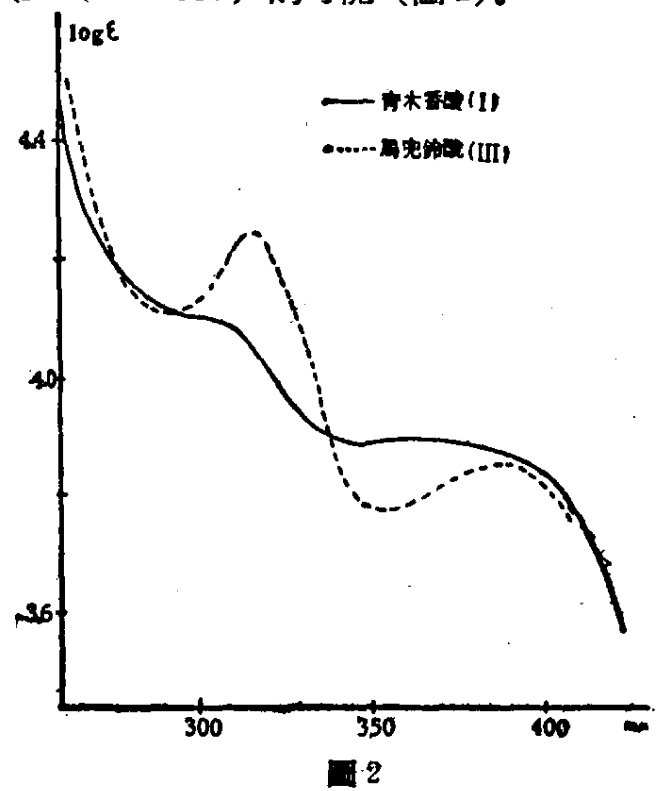

